\title{
The Importance of Endospore-Forming Bacteria Originating from Soil for Contamination of Industrial Food Processing
}

\author{
Marc Heyndrickx \\ Technology and Food Science Unit, Institute for Agricultural and Fisheries Research (ILVO), \\ Brusselsesteenweg 370, 9090 Melle, Belgium \\ Correspondence should be addressed to Marc Heyndrickx, marc.heyndrickx@ilvo.vlaanderen.be
}

Received 28 February 2011; Accepted 5 July 2011

Academic Editor: Ismail Saadoun

Copyright ( 92011 Marc Heyndrickx. This is an open access article distributed under the Creative Commons Attribution License, which permits unrestricted use, distribution, and reproduction in any medium, provided the original work is properly cited.

Specific endospore formers have become important contaminants in industrial food processing. The direct or indirect soil route of contamination or dispersal is the start of events or processes in the agrofood chain that eventually leads to important problems or concerns for food safety and/or quality. Three important food sectors are discussed in this paper. In the dairy sector, Bacillus cereus, the most important pathogen or spoilage organism in this sector, and Clostridium tyrobutyricum, the most important spoiler in certain cheeses, both contaminate pasteurized milk through the faecal and/or (at least for B. cereus) the direct soil route. In the fruit juice industry, Alicyclobacillus acidoterrestris, present on raw fruits, has become a major quality-target organism. In the readyto-eat food sector, B. cereus and other aerobic endospore formers are introduced via vegetables, fruits, or herbs and spices, while anaerobic spore formers like nonproteolytic Clostridium botulinum and Clostridium estertheticum pose safety and spoilage risks in chilled packaged foods, respectively.

\section{Introduction}

There is a clear association between soil-borne endospore forming bacteria and food contamination. The spore formers implicated belong both to the strictly anaerobic ("the clostridia") and to the aerobic (the genus Bacillus and related genera) phylogenetic groups of microorganisms. Several reasons can be proposed to explain this phenomenon, and most are related to some general characteristics of the spores, which are formed at the end of the growth phase within the vegetative mother cell acting as sporangium (hence, endospores) and released in the environment as survival structures (Figure 1). These are (1) their ubiquitous presence in soil, (2) their resistance to heat in common industrial processes such as pasteurization, (3) the adhesive characters of particular spores that facilitate their attachment to processing equipment, and (4) their ability to germinate and grow in favorable conditions [1]. Several spore formers either need or tolerate specific conditions for germination and growth, which all can occur in food even in combination, such as low or high temperatures and anaerobic or acidophilic conditions. The concerted characteristics of spores and vegetative cells of particular soil-borne species make them potential sole surviving and growing contaminants in specific industrially processed foods. Some of them seem even to be of more recent concern, which might be the result of increasing tolerance, adaptation, or resistance of spores or vegetative cells of particular spore-forming species to conditions or treatments that were previously presumed either to stop growth (low temperatures and low $\mathrm{pH}$ ) or to inactivate all living material (ultrahigh heat treatment (UHT) and commercial sterilization). The food industry seems to be increasingly confronted with tolerant or resistant spore formers that might be side effects of the use of new ingredients, the application of new processing and packaging technologies, and the highly increased production and marketing of convenience foods. In the last two decades, there has been a significant increase in the production and sale of ready-to-eat or ready-to-cook foods stored under refrigerated conditions [2]. These products are known as cooked-chilled foods or as refrigerated processed foods of extended durability (REPFEDs), such as vegetable purées and ready-to-eat meals. They are typically processed with a gentle heat treatment 


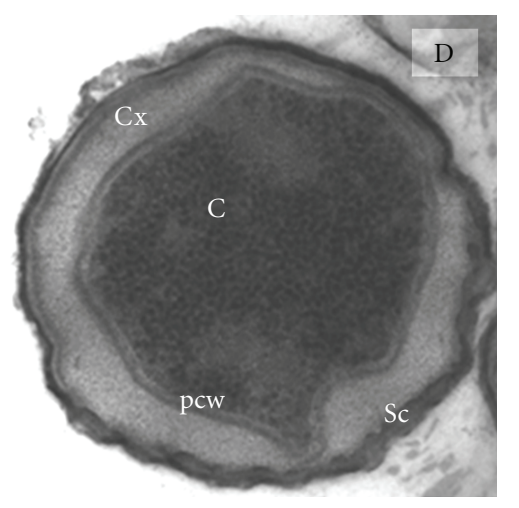

Figure 1: Electron micrograph of a B. cereus spore, 146.000x. c, spore core; cx, spore cortex; sc, spore coat; pcw, primordial cell wall. Adapted from Scheldeman et al. [3].

(65-95 ${ }^{\circ} \mathrm{C}$, enabling survival of spores) and are chill-stored with (frequently) modified-atmosphere packaging for an extended durability (from a few days up to 3 months), whilst preserving the product attributes such as organoleptic quality and safety. REPFED food items, as well as dairy products (milk and desserts) with a shorter shelf life $(<10$ days), are specific niches for psychrotolerant spore-forming bacteria. Spore formers cause two kinds of problems in the food industry. In the first place, there are some food-borne pathogens such as Bacillus cereus and Clostridium botulinum. Secondly, there is the reduction of shelf life and food spoilage. Microbial spoilage of food is usually indicated by changes in texture or the development of off-flavours.

In this paper, recent data revealing the role of soil as primary contamination source for spore formers in food (B. cereus, Alicyclobacillus acidoterrestris, Clostridium tyrobutyricum) or extending our knowledge on specific soil-borne spore formers in food (several Clostridium spp. such as $C$. estertheticum) are discussed.

\section{Bacillus cereus}

2.1. Presence in Soil. B. cereus sensu stricto (hereafter called $B$. cereus for simplicity) is a member of the $B$. cereus group or also called B. cereus sensu lato (Table 1), which can be divided into seven major phylogenetic groups each corresponding to a specific "thermotype", showing clear differences in ability to grow at low or high temperatures [4]. B. cereus is a ubiquitous organism present in many types of soil, sediments, dust, and plants. Soil is heavily contaminated with $B$. cereus spores which can occur in a range from 4 up to $6 \log$ spores per gram farm soil (Table 2). It has long been believed that this organism has a saprophytic life cycle in soil with the presence of spores that only germinate and grow upon contact with soil-associated organic matter (i.e., nutrientrich conditions). However, in laboratory experiments with liquid soil extract and artificial soil microcosms, it was observed that B. cereus (as well as other soil-isolated Bacillus species) displayed a complete life cycle (germination, growth, and sporulation) and adapted to translocate in soil by switching from a single-cell phenotype to a multicellular one with the formation of filaments and clumps that encased the
TABLe 1: Phylogenetic structure of the B. cereus group and characteristics based on data from Guinebretière et al. [4].

\begin{tabular}{|c|c|c|c|}
\hline $\begin{array}{l}\text { Phylogenetic } \\
\text { group }\end{array}$ & $\begin{array}{l}\text { Association to } \\
\text { a currently valid } \\
\text { species }\end{array}$ & $\begin{array}{l}\text { Growth } \\
\text { temperature } \\
\text { range in }{ }^{\circ} \mathrm{C} \\
\text { (\% of strains } \\
\text { growing at } \\
\text { lowest } \\
\text { temperature }{ }^{\mathrm{a}} \text { ) }\end{array}$ & $\begin{array}{l}\text { Association } \\
\text { to cases of } \\
\text { food } \\
\text { poisoning } \\
(\% \text { of } \\
\left.\text { strains }^{b}\right)\end{array}$ \\
\hline I & B. pseudomycoides & $10-40(75 \%)$ & No $(0 \%)$ \\
\hline II & $\begin{array}{l}\text { B. cereus } \mathrm{II}^{\mathrm{c}} \text { and } B . \\
\text { thuringiensis II }\end{array}$ & $7-40(73 \%)$ & Yes $(21 \%)$ \\
\hline III & $\begin{array}{l}\text { B. cereus III (emetic } \\
\text { strains), } B \text {. } \\
\text { thuringiensis III, B. } \\
\text { anthracis }\end{array}$ & $15-45(100 \%)$ & Yes $(33 \%)$ \\
\hline IV & $\begin{array}{l}\text { B. cereus IV and } B . \\
\text { thuringiensis IV }\end{array}$ & $10-45(100 \%)$ & Yes $(22 \%)$ \\
\hline $\mathrm{V}$ & $\begin{array}{l}\text { B. cereus } \mathrm{V} \text { and } B \text {. } \\
\text { thuringiensis } \mathrm{V}\end{array}$ & $8-40(14 \%)$ & Yes $(12 \%)$ \\
\hline VI & $\begin{array}{l}B . \\
\text { weihenstephanensis } \\
\text { and B. mycoides }\end{array}$ & $5-37(40 \%)$ & No $(0 \%)$ \\
\hline VII & "B. cytotoxicus" & $20-50(100 \%)$ & Yes $(50 \%)$ \\
\hline
\end{tabular}

a percentage of strains in the study of Guinebretière et al. [4] which could grow at lowest temperature of indicated temperature range for each phylogenetic group; ${ }^{b}$ percentage of strains for each phylogenetic group in the study of Guinebretière et al. [4] which could be associated to food poisoning foods; ' proposal of Guinebretière et al. [4] to add phylogenetic number (I to VII) to the species name; ${ }^{\mathrm{d}}$ not yet validated species.

ensuing spores in an extracellular matrix [5]. In addition to a full life cycle in soil, $B$. cereus is also adapted to a lifestyle in the animal (e.g., soil animals such as earthworms [6]) or human gut, where it can behave as a pathogen or as a part of the intestinal microbiota, as well as to growth in food and feed. Bacillus thuringiensis, being an insect pathogen of the B. cereus group, is likewise a ubiquitous soil microorganism, but it is also found on the phylloplane and in insects. Presumably, B. thuringiensis proliferates in the guts of insects and is then released into soil where it can subsequently proliferate under favorable nutrient conditions [7]. Less is known on the ecology of the other members of the B. cereus group (the psychrotolerant species: Bacillus mycoides and Bacillus weihenstephanensis and the mesophilic species: Bacillus pseudomycoides), except that they have been isolated from a wide variety of environmental niches such as soils, sludge, arthropods, earthworms, and rhizospheres [7]. It has been speculated that climate change may modify the spreading of $B$. cereus hosts (wildlife, insects, earthworms) [8]. Alternatively, B. cereus with its wide adaptive strategy to changing environments through signal transduction mechanisms likely will adapt to environmental (climate) changes for example, climate change could modify the distribution of the phylogenetic groups of B. cereus in soil. This adaptation might contribute at the end of the chain to a progressive change in prevalence or concentration in foods. 
Applied and Environmental Soil Science

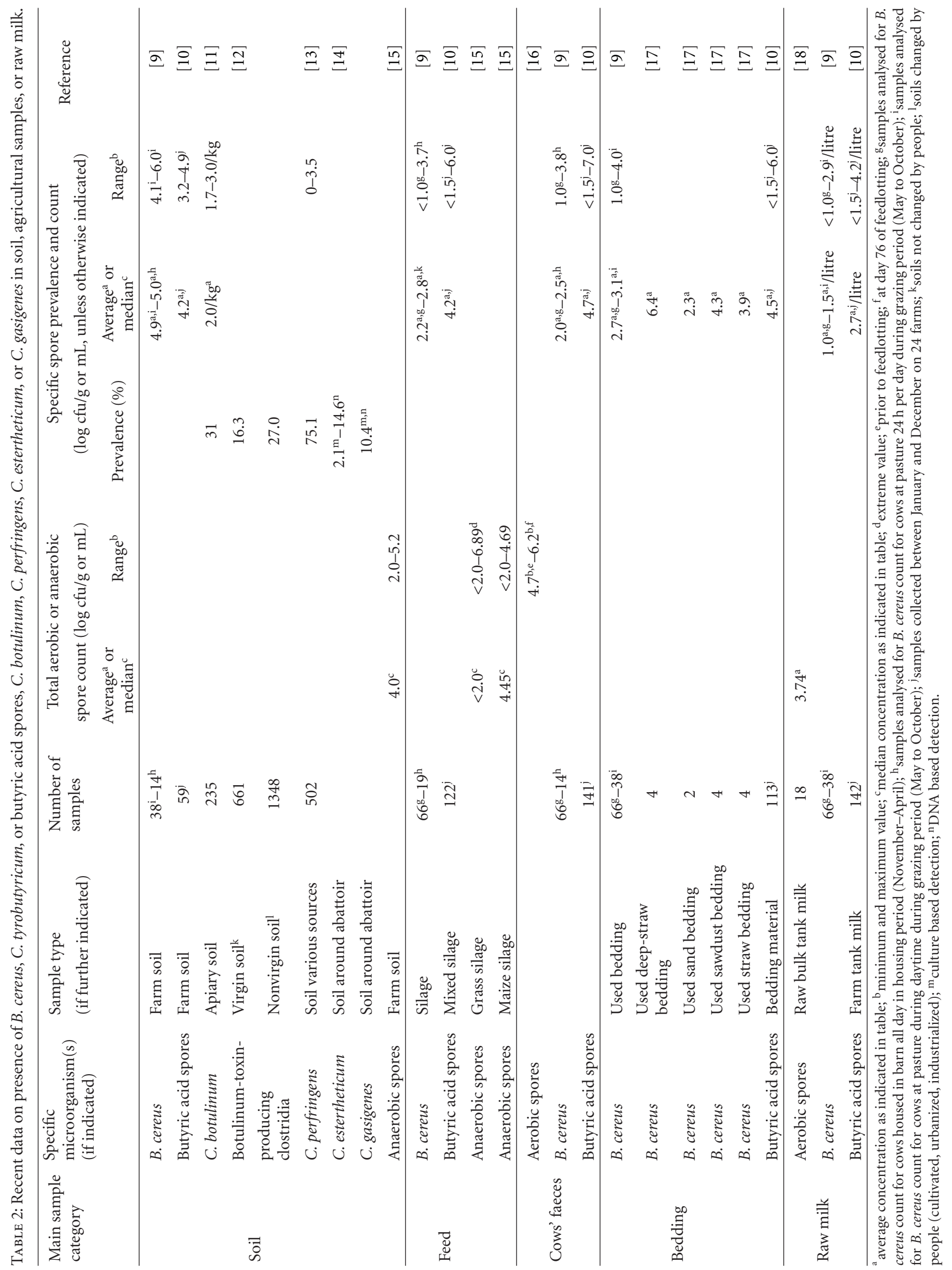


2.2. Transfer from Soil to Food. Soil, together with air, is probably the primary source of food contamination. Being a soil resident, $B$. cereus is part of the microbiota of plant raw materials, attached as vegetative cells or spores. At harvest, this plant raw material can be used for direct human consumption as fresh produce, as ingredients for food or feed production, or directly as animal feed. Dairy cows consuming such feed will excrete $B$. cereus spores in the faeces, and these spores will contaminate the raw milk causing potential safety or shelf-life problems (see Section 2.3). B. cereus is the causative agent of two distinct types of food poisoning, the emetic and diarrhoeal syndrome (reviewed by Arnesen et al. [19]). On the other hand, as B. cereus is not dominant in the microbiota of plant raw materials, fresh produce for direct human consumption (fresh vegetables and fruits, fresh herbs and spices, fresh potatoes) has not been reported in association with outbreaks or cases of food-borne illness caused by this organism [20]. Nevertheless, recent investigations in Denmark have shown that $B$. thuringiensis strains, in some cases indistinguishable from the commercial strains used in microbial bioinsecticides, were present on fresh vegetables (e.g., fresh cucumbers and tomatoes) in Danish retail shops to levels that may exceed $10^{4} \mathrm{cfu} \mathrm{g}^{-1}$ [21]. Since these strains harboured genes encoding enterotoxins, increased concern regarding the residual amount of $B$. thuringiensis insecticide on vegetable products after harvest may be imminent. Despite these observations, problems of $B$. cereus food poisoning and/or spoilage are mainly restricted to pasteurized or dried products manufactured in food processing units. A combination of the specific attributes of the spores and of the resulting vegetative cells give $B$. cereus a huge advantage not only over nonspore formers, but also over other spore formers, and they explain why this organism is a special threat to the food processing industry. Firstly, like all bacterial spores, $B$. cereus spores are resistant to heat and desiccation and they will thus survive food-processing steps, such as pasteurization or thermization and dehydration or drying, that all eliminate or reduce vegetative cells. de Vries [22] reported decimal reduction times at a heating temperature of $95^{\circ} \mathrm{C}\left(\mathrm{D}_{95}\right.$-values) varying from around 5 to as high as 80 minutes for spores of naturally occurring $B$. cereus strains. As a result, a final product may be contaminated with spores that face little or no competition from vegetative species that would otherwise outgrow B. cereus.

A second aspect is that $B$. cereus spores, which are introduced into the food production chain via plant ingredients or via milk or milk powder, can efficiently adhere to equipment surfaces and pipelines because of the hydrophobic character of the exosporium and the presence of appendages on the spore surface (Figure 1). According to Wijman et al. [23], a B. cereus biofilm may particularly develop in a partly filled industrial storage or a piping system, and such a biofilm acts as a nidus for formation of spores that can subsequently be dispersed by release into the food production system. Spores embedded in biofilms are protected against disinfectants [24]. A third aspect is the use of extended refrigeration in food production and distribution, as well as in the kitchen, to increase the shelf life of processed foods. An important feature of B. cereus strains, especially diarrhoeal and food-environment strains (but, however, virtually none of the emetic strains), is psychrotolerance; that is to say, growing at temperatures $\leq 7^{\circ} \mathrm{C}$ [25]. Moreover, it is important to note that the majority of $B$. cereus strains are able to start growing from $10^{\circ} \mathrm{C}$, which represents mild temperature abuse conditions.

Due to its ubiquitous presence in soil and on plant material which is used for a variety of purposes and in food processing environments, as well as its special characteristics described above, the presence of $B$. cereus (and other species of the $B$. cereus group) seems to be inevitable in many types of foods and ingredients. These include raw foods such as fresh vegetables and fruits, including sprouted seeds, raw herbs, and raw milk, ingredients such as pasteurized liquid egg and milk powder, flour, dried spices and herbs, and all kinds of processed foods such as rice, pasta, cereals, dried potato products, meat products, sauces, dehydrated soups, salads, cut and prepacked vegetables and prepacked sprouts, dehydrated mushrooms, chilled readyto-eat and ready-to-cook meals, Chinese meals, vegetable and potato purées, pasteurized milk and dairy products, bakery products, desserts and custards, powdered infant formulae, and chocolate $[19,26]$. The level of $B$. cereus in raw foods and in processed foods before storage is usually very low ( $<100$ spores/g or $\mathrm{mL}$ ) and poses no direct health or spoilage concern. However, upon storage of processed foods or the use of contaminated ingredients in complex foods, conditions may allow germination and outgrowth of spores to levels that present hazards for consumers. Some countries have specific microbiological criteria or guidelines for this food-borne pathogen; these are generally in the range of $>10^{4}-10^{5} \mathrm{cfu} / \mathrm{g}$. Outbreaks of $B$. cereus food-borne illness have been associated with a diversity of foods such as takeaway meals and lunch boxes, oriental meals, cold dishes, minced meats, pita, merguez (North African sausage), chicken, sprouts, meals with rice, boiled and fried rice, pasta salad, pastry, spaghetti, noodles, spices, sauces, soups, stew, quiche, puddings and cream pastries, pasteurized milk and milk products, mashed potatoes and potato salad with mayonnaise, vegetable purée, salad, fish, orange juice, and onion powder ([19, 26]; K. Dierick, pers. comm.).

2.3. From Soil to the Milk Chain. In the last decades, the importance of the psychrotolerant aerobic endospore formers for the keeping quality of milk has increased significantly, owing to extended refrigerated storage of raw milk before processing on the farm, higher pasteurization temperatures, reduction of postpasteurization contamination, and prolonged shelf-life requirements of the consumer product. It should be remembered that pasteurization activates spore germination and thus enhances vegetative cell growth. Growth of $B$. cereus in pasteurised milk is considered the main limiting factor determining the shelf life of this food product. Too high levels of $B$. cereus in pasteurized milk before the end of shelf life or prolonged refrigerated storage cause common structural defects known as sweet curdling and bitty cream (reviewed by Heyndrickx et al. [27]). B. cereus diarrhoeal cases or outbreaks associated with milk or dairy products are scarce, although $B$. cereus is 


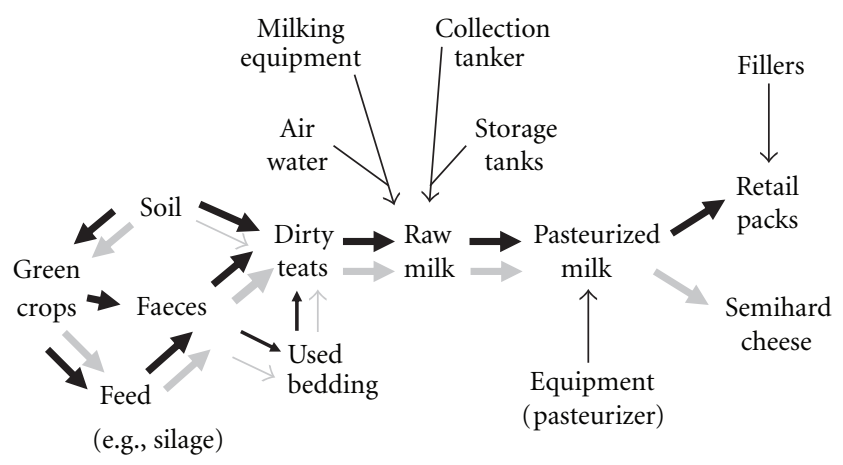

Figure 2: Contamination routes of spores of B. cereus (black arrows) and C. tyrobutyricum (grey arrows) in the dairy production chain. The importance of contamination sources and routes is indicated by the size of arrow.

commonly isolated from pasteurized milk. This may be due to the fact that in the cold dairy chain, selection occurs for psychrotolerant members of the $B$. cereus group, which are mostly strains of $B$. weihenstephanensis. It has been shown that these strains are less toxigenic than mesophilic B. cereus strains and are thus less likely to cause illness [28]. Emetic food poisoning related to the consumption of dairy products has been reported (see references in [28]). Although the overall prevalence of emetic strains in the dairy production chain is very low $(<1 \%)$, colonization and proliferation of emetic $B$. cereus was observed at particular farms with saw dust bedding as a likely contamination source for the raw milk, and in a silo tank at a dairy plant [28]. As the general level of spores of emetic-toxin-producing strains in milk is low $(<1000 \mathrm{cfu} /$ litre $)$, there is no risk associated with consumer milk provided that the milk is properly refrigerated. If contaminated milk is used for milk powder, a risk to the consumer exists if this milk powder is used in baby food or as raw ingredient in foodstuffs, where proliferation of $B$. cereus may occur, and there have been reports of emetic food poisoning episodes where contaminated milk powder was a likely source (see references in [28]).

From the above, it is not surprising that B. cereus is a major concern of the dairy industry, because it seems impossible to avoid its presence in milk completely. In the Netherlands, a maximum B. cereus spore limit in farm tank milk of $3 \log$ spores/litre has been deemed necessary to achieve a shelf life for pasteurized milk of at least 7 days [9]. During recent decades, several possible contamination routes for $B$. cereus in pasteurized milk have been described, with either raw milk or postpasteurization contamination of the pasteurized milk being the source (Figure 2). As for the raw milk route of contamination, only in recent years evidence has been obtained using sensitive detection methods, as $B$. cereus levels in raw milk are usually very low (e.g., average of $1.2 \log$ spores/litre ([9]; see Table 2), and by molecular typing. Raw milk in the farm tank is contaminated with $B$. cereus spores via the exterior of the cow's teats and through improperly cleaned milking equipment. Contamination of the exterior of the teats occurs when they are contaminated with dirt; during the grazing season of the cows, this dirt is mainly soil, while during the housing season the attached dirt is mainly faeces and bedding material. During milking, this dirt is rinsed off and spores present in the dirt can contaminate the raw milk. As a result, soil, feed (through excretion of spores in faeces), and bedding material are the major sources of contamination of raw milk with B. cereus, but the relative contribution of these sources will be different according to the housing conditions of the cows (i.e., outdoor grazing versus indoor housing in stables) (Figure 2). Additional evidence that soil is the initial contamination source in the grazing season (called "a pasturing effect") was provided in a comparative study of raw milks from organic dairy farms (with obligatory grazing during the summer and autumn) and conventional farms (with less grazing during summer and autumn); higher incidences of $B$. cereus were found in milks from organic farms [29]. Soil on farms is very frequently contaminated with $B$. cereus $(65-100 \%)$ and can contain up to $10^{6} \mathrm{~B}$. cereus spores/g, but high variations (up to $3 \log$ ) can occur between sampling sites or times (Table 2).

Another important source of contamination of raw milk with $B$. cereus spores, identified by different studies, is cows' faeces or dung. Highly variable levels of B. cereus spores (from below the detection limit up to $10^{5} \mathrm{cfu} / \mathrm{g}$ ) can be present in different samples of faeces, but the average concentration seems to be around $2 \log \mathrm{cfu} / \mathrm{g}$ (Table 2). It is assumed that Bacillus spp. are not commensals of the cow's gastrointestinal tract but are introduced via the feed and subsequently shed in the faeces [16]. Thus B. cereus spores present in faeces probably originate from feed and from soil, either directly (during grazing on the pasture when soil is also taken up by the cows) or indirectly (through the green crops used as feed or feed ingredients). Using molecular typing, silage has been shown to be a significant source of contamination of raw milk with spores, including those of $B$. cereus that may occur in levels up to $10^{4} \mathrm{cfu} / \mathrm{g}$ (Table 2). The spores in silage principally arise from soil and farmyard manure. In maize silage, lower concentrations of total spores of aerobes than in grass silage $\left(10-10^{3} \mathrm{cfu} / \mathrm{g}\right.$ versus $10^{2} 10^{5} \mathrm{cfu} / \mathrm{g}$ ) were found, which can be explained by the fact that grass silage is more contaminated with soil or faeces than maize silage [30]. Grass samples taken close to soil or faeces contained levels of $10^{1}-10^{3}$ B. cereus spores/g, while this was $<10$ spores/g for grass without soil. Nowadays, ensiled grass and maize form the major part of the feed ration of cattle in Europe and North America during the whole milking year. It is important to prevent outgrowth of spores in silage by application of special cultures of lactic acid bacteria or chemical additives to improve aerobic stability of the silage [9]; however, these measures are not always used on the farm. In the housing period of the cows, feed is the only source of spores, and teats become contaminated mainly through the bedding material that is contaminated with faeces (Table 2). It was found that a spore content of the bedding material exceeding $10^{4} \mathrm{spores} / \mathrm{g}$ increased the risk for elevated spore concentrations in the bulk tank milk [17].

However, using a predictive modeling approach, it was found that soil was far more important than feed (and hence bedding material) as source of $B$. cereus spores in farm tank milk: when soil was the source of B. cereus spores, $33 \%$ of simulated spore concentrations in farm tank milk in the 
Netherlands were above the maximum spore limit of $3 \mathrm{log}$ cfu/litre, while this was only $2 \%$ when feeds (through faeces and bedding) were the sources of spores [31]. According to the model, during the housing period, the concentration of spores of $B$. cereus in raw milk is almost always less than the maximum spore limit. During the grazing period, a $99 \%$ reduction of the average concentration of $B$. cereus spores in raw milk might be achieved by minimization of contamination of teats with soil and optimization of teat cleaning efficiency at all farms in the Netherlands. Another control option would be to house cows on damp and rainy days during summer, when the concentration of $B$. cereus spores in soil is higher [32]. During such a housing period, care would have to be taken that the initial spore concentration in feeds is $<3 \log \mathrm{cfu} / \mathrm{g}$ and that the $\mathrm{pH}$ of the ration offered to the cows is below 5. Vissers et al. [9] pointed to the fact that under certain circumstances, especially wet conditions, transmission of substantial amounts of soil $(>1 \mathrm{mg} /$ litre milk) can occur, leading to spore levels in milk exceeding the maximum spore limit in the Netherlands. Hence, for the dairy industry, control of the soil contamination pathway is most important.

2.4. Transfer from Soil to Vegetables, Fruit, and Ready-toEat Meals. Contamination of vegetables and fruit frequently occurs either directly through soil or indirectly through agricultural practices such as irrigation with polluted water or fertilization with manure or sewage sludge. Also, wild and domestic animals can contaminate crops or irrigation water, and farm workers and other human handlers further on in the food chain have important roles in the microbiological safety of produce given the possibility of crosscontamination. Fresh crops (with the exception of sprouted seeds (reviewed by Bassett and McClure [20]) have not yet been reported as sources of $B$. cereus food-borne outbreaks and incidents. On the other hand, prepared salads, with a variety of other ingredients besides vegetables and/or fruit, and which are sold in ready-to-use or ready-to-eat formats and rely upon refrigeration for preservation, have been increasingly associated with $B$. cereus or Bacillus spp. food poisoning in recent years. In England and Wales in the period 1992-2006, 4\% of the outbreaks associated with prepared salads were caused by Bacillus spp. [33]. Besides prepared salads, cooked-chilled foods, also known as REPFEDs, are increasingly popular. To this category of foods belong the vegetable purées, which are prepared by steam cooking of washed vegetables $\left(10-50 \mathrm{~min}\right.$. at $\left.80-100^{\circ} \mathrm{C}\right)$, mixed with other ingredients (UHT-cream, milk proteins, starch, salt) and pasteurization in their packaging $\left(10 \mathrm{~min}\right.$. at $\left.80-90^{\circ} \mathrm{C}\right)$. Although these products are relatively stable up to 21 days when stored at $4^{\circ} \mathrm{C}$, the processing conditions will not completely eliminate the spore formers that can develop during cold storage. Vegetable purées were already the source of a severe fatal $B$. cereus outbreak in a French nursing home for elderly persons, and this episode led to the discovery of a new B. cereus diarrhoeal toxin, cytotoxin K [34]. In cooked, pasteurized, and chilled vegetable purées (broccoli, carrot, courgette, leek, potato, split pea), aerobic endospore formers are the dominant microbiota (albeit at low numbers of $\leq 2$ $\log \mathrm{cfu} / \mathrm{g}$ before storage) and an increase in their numbers (up to 7-8 $\log \mathrm{cfu} / \mathrm{g}$ ) depends on the storage temperature and the type of vegetable [35]. Courgette purée (also called zucchini purée) consistently supported the most rapid microbial growth at low temperature and was the product most prone to spoilage (pack swelling and/or off-odours). By means of molecular typing, it could be established that the outgrowth at 10 or $7^{\circ} \mathrm{C}$ is of psychrotolerant strains that originated in the zucchini, while the strains from the dehydrated texturing agents (milk proteins and starch) were mesophilic strains that were genetically different from the zucchini strains and which probably contributed less to the growth at $10^{\circ} \mathrm{C}$ [36]. Furthermore, it was found that the initial source of contamination for the zucchini, with psychrotolerant $B$. cereus, was soil. These data indicate that processing and storage of vegetables lead to selection of $B$. cereus strains and that this is enabled by the fact that soil as the initial source of contamination is a reservoir of a large diversity of strains. The importance of this genetic diversity was illustrated by a quantitative exposure assessment that took into account the heterogeneous population of $B$. cereus in courgette puree [37]. The model predicted that at the time of consumption, $B$. cereus may be present in all purée packages, but that not all B. cereus genetic groups (I to VII as described in Table 1) were present in all packages. The highest food poisoning risk in REPFED foods was predicted to be associated with members of the psychrotolerant $B$. cereus group II because of their predicted prevalence $(16.8 \%$ of the $B$. cereus population per package) and concentrations at the time of consumption ( $2.5 \%$ of the packages contaminated with $>6.7 \log \mathrm{cfu} / \mathrm{g})$. Although some strains implicated in $B$. cereus food poisoning belong to psychrotolerant genetic group II, it must be noted that most strains related to cases or outbreaks belong to mesophilic genetic groups III and IV. This may explain why most reported cases have been associated with incidents of storage temperature abuse.

\section{Alicyclobacillus acidoterrestris}

3.1. Spoilage of Fruit Juices by Alicyclobacilli. In the 1990s, observations of episodic spoilage of fruit juice and similar products by $A$. acidoterrestris have started in Europe, the USA, and Japan [38]. Until then, it was believed that the high acidity of fruit juices $(\mathrm{pH}<4)$, combined with pasteurization in the fruit beverage industry (hot-fill and hold for $2 \mathrm{~min}$. at $88-96^{\circ} \mathrm{C}$ ), was sufficient to render these products commercially sterile without the use of preservatives. More recently, new species were isolated: $A$. acidiphilus, which is closely related to $A$. acidoterrestris, and A. pomorum from spoiled juice products, and $A$. herbarius from spoiled herbal tea [39-41].

A. acidoterrestris survives the hot-fill and hold processes because of the heat resistance of the spores (D-values of $65.6 \mathrm{~min}$ at $85^{\circ} \mathrm{C}$ and $11.9 \mathrm{~min}$ at $91^{\circ} \mathrm{C}$ in orange juice [42]), which germinate following heat shock, and the organism starts to grow in the product up to a level of $10^{5}-10^{6}$ $\mathrm{cfu} / \mathrm{ml}$ because of its unique physiological characteristics (growth from $\mathrm{pH}$ 2.5-6.0 with optima around $\mathrm{pH}$ 3.5-5.0 and from $20-60^{\circ} \mathrm{C}$ with optima at $\left.42-53^{\circ} \mathrm{C}\right)$. Storage of 
pasteurized fruit juices below $20^{\circ} \mathrm{C}$ would be sufficient to prevent outgrowth of spores, but these juices are usually distributed under ambient conditions.

Spoilage (long before the expiration date) is sometimes associated with a slight increase in turbidity and white sediment at the bottom of packages, but the most important fault is taint of strong medicinal or antiseptic flavour caused mainly by the production of guaiacol, but also by 2, 6-dibromophenol and 2, 6-dichlorophenol [43]. Affected products are pasteurized fruit juices (mainly apple and orange) and fruit juice blends, but there have also been reports of spoiled carbonated fruit drinks, berry juice containing iced tea, and diced canned tomatoes [44]. Although spoilage is incidental, requiring a combination of adequate conditions such as available oxygen (determined by the head space in the package or container), nutrient availability, taint precursors, and high temperature for a long time, all fruit juice manufacturers have started quality assurance programs to monitor and control levels of Alicyclobacillus species in raw materials and fruit concentrates. Between $14.7 \%$ and $83 \%$ of fruit juices, fruit concentrates, or fruit juice products have been found positive for Alicyclobacillus [44]. Recently, A. acidoterrestris has also been isolated from (nonspoiled) exotic fruit juices such as passion fruit juice (incidence rate of $28 \%, n=57$ ), but not from pineapple juice [45]. As passion fruit grows close to the soil and has a rough surface, this contamination emphasizes the need for improving the efficiency of fruit washing and disinfection and the application of good agricultural practices, avoiding the harvesting of fruit that has fallen on the ground.

\subsection{Presence of Alicyclobacilli in Soil. As A. acidoterrestris is} mainly soil borne, unwashed or insufficiently washed raw fruit, which is contaminated on the surface with soil, and poor hygiene measures in fruit juice concentrate production are the most likely contamination sources. More than onethird of all fruits sampled at two juice-processing facilities were contaminated with presumptive Alicyclobacillus species [46]. A. acidoterrestris has also been isolated from process water plant [47], and Alicyclobacillus strains have been found in liquid sugar [48].

Recently, several Alicyclobacillus species have been isolated from orchard soils: A. acidoterrestris and A. acidocaldarius from orchard soil $(\mathrm{pH}$ 5.9-6.7) collected from an apple and pear farm in South Africa [49], A. acidoterrestris and $A$. contaminans as major species (besides several other minor Alicyclobacillus species) from several fruit (banana, blueberry, chestnut, grape, kiwi, orange, pear, persimmon, strawberry) orchard soils in Japan [50]. Several of the isolated species produced guaiacol, but the production levels were strain dependent, even within $A$. acidoterrestris. By RAPD typing, it was shown that identical strains were present in pear concentrate and soil outside the factory, indicating soil as the source of the Alicyclobacillus spores [51].

\section{Clostridia}

4.1. Importance of Soil Dwelling Clostridia. Like the aerobic spore formers, also the clostridia are abundantly present in soil (Table 2) and can survive for extended periods of time in soil by maintaining very low levels of metabolic activity [52]. Clostridial plate counts on four dairy farms in Canada ranged from detection limit to $5.2 \mathrm{log}$ cfu per gram soil [15]. Several species have been isolated from soil: for example, 16 species in Korean soil from 5 different areas [53], 54 species in 117 soil samples (on average 7.1 species per sample) from different geographic zones in Costa Rica [54]. This indicates that soil can be a potential reservoir of harmful clostridial species. Most soil samples (approximately $70 \%, n=502$ ) from city, suburban, or farm origin in the Pittsburgh area (USA) contained the toxigenic species Clostridium perfringens in levels ranging from 0 to $10^{3} \mathrm{cfu}$ per gram soil [13]. Although C. perfringens type A, which is usually involved in food poisoning, was predominant among the soil isolates in that study, soil appeared not to be a major reservoir for isolates causing food poisoning but a potential reservoir for plasmid-borne cpe enterotoxin positive isolates causing non-food-borne gastrointestinal diseases. C. perfringens together with Clostridium sordelli was also the most prevalent toxigenic species in Costa Rican soil [54] and was detected in all sampling locations in Korea [55]. For botulinum toxinproducing clostridia, prevalence ranges from $5.7 \%$ to $24.3 \%$ depending on the country of investigation [12]. In that study, a higher prevalence was observed in nonvirgin soil (i.e., cultivated, urbanized, and industrialized soil: $27 \%$ ) than in virgin soil (i.e., soil that had not been changed by people: $16.3 \%$ ) in five geographical regions of Argentina. Also in soil collected in honey-producing apiaries in Finland, a high prevalence of C. botulinum ( $31 \%, n=235)$ was found as was also the case for beeswax $(23 \%, n=176)$ [11]. This indicates that soil-derived spores of $C$. botulinum, carried into the hive by bees, may accumulate in beeswax, but they may also directly contaminate the honey during the extraction process because of poor hygiene. Honey is one of the most important sources of and the only proven food item associated with $C$. botulinum spores responsible for infant botulism.

Besides neurotoxigenic species, several Clostridium species occurring in soil are important as spoilers of pro-cessed foods such as the REPFED foods with modified atmosphere packaging (vacuum or anaerobic atmosphere) and semihard cheeses.

4.2. Toxigenic and Spoilage Clostridia in Chilled Foods. C. botulinum is divided into four groups, of which the proteolytic group I (producing type $\mathrm{A}, \mathrm{B}$, and $\mathrm{F}$ neurotoxins) and the nonproteolytic group II (producing type B, E, and F neurotoxins) are causing human botulism. Group II isolates are psychrotolerant, growing at temperatures as low as $3^{\circ} \mathrm{C}$, and produce spores which are less heat resistant than those of group I. This explains the fact that in modern food processing with mild processing (e.g., heating) conditions and extended shelf lives based on chilled storage combined with modified atmosphere or vacuum packaging, especially C. botulinum group II poses a safety hazard. Under these conditions, the growth of aerobic bacteria is restricted and thus shelf life extended, but it can also provide an environment conducive to the growth of anaerobic bacteria such as clostridia. It is estimated that more than $1.5 \times 10^{10}$ chilled 
prepared ready meals have been consumed in Europe in the last 20 years and that this consumption increases by at least $10 \%$ per annum [56]. The use of HACCP for the production of chilled foods is specified in European hygiene laws, and a number of guidelines, advice, and recommendations exist emphasizing the importance of HACCP and chill storage. The number of botulism cases caused by ready-to-eat food consumption has increased and has been reported worldwide during the last 25 years [57]. Although most botulism cases and $C$. botulinum spore contaminations are associated with fish or seafood products, a high prevalence of $C$. botulinum type $\mathrm{E}$ spores has been found in meat and in potato peels, the latter reflecting the high spore level in soil. A literature examination has indicated that, given the fact that nonproteolytic $C$. botulinum could form toxin in $\leq 10$ days at $\leq 8^{\circ} \mathrm{C}$ according to predictive models representing worst-case scenarios, commercial short shelf-life ( $<10$ days) chilled foods have not been reported yet as being associated with foodborne botulism when stored correctly, but both proteolytic and nonproteolytic $C$. botulinum have caused outbreaks from these foods when temperature abuse had occurred [56]. Nevertheless, precise safety margins with respect to foodborne botulism seem not to be well defined for these food products, and changes in industrial practice (e.g., extending shelf life), processes, or ingredients could alter the safety risk.

Several psychrophilic and psychrotolerant species including C. algidicarnis, C. algidixylanolyticum, C. estertheticum, C. frigidicarnis, and $C$. gasigenes have been implicated in red meat spoilage (softening of the meat, large amounts of drip, offensive odour) [58]. Of these species, C. estertheticum (subspecies estertheticum and laramiense) and C. gasigenes additionally produce gas and have been recognized as causative agents of "blown pack" spoilage of vacuum-packed chilled meats at normal storage temperatures $\left(-1.5\right.$ to $\left.2^{\circ} \mathrm{C}\right)$. These two spoilage clostridial species have been found frequently in beef slaughterhouses and their environments, especially at areas prior to hide removal [14]. It is therefore assumed that hides and feces are the main reservoirs for these organisms in the slaughterhouse. Previously, it had already been suggested that soil particles attached to hide or present in feces are the most probable primary reservoir from which "blown pack" clostridia are introduced onto carcasses [59]. There is no evidence that these clostridia are present in the gut of farm animals. Both C. estertheticum and C. gasigenes have been detected in soil outside an abattoir, strengthening the soil route hypothesis [60]. Hygienic carcass dressing will become increasingly important to keep contamination with "blown pack" spoilage clostridia to a minimum and to maximize shelf life of vacuum-packed chilled meats as it has been found in challenge tests that 1 C. estertheticum spore in a vacuum pack may already present a risk of spoilage before the estimated end of shelf life [61]. As a first step, it may be envisaged to entail further control on and/or pretreatment of dirty animals prior to their entry into the slaughterhouse combined with sporicidal sanitation of high risk sources of cross-contamination.

4.3. Clostridium tyrobutyricum in Cheese Making. Spores of butyric acid bacteria can cause spoilage of semihard cheeses with long ripening times such as Gouda and Emmenthaler. Mostly Clostridium tyrobutyricum is implicated in the socalled late blowing defect of this kind of cheeses. This organism is able to convert lactic acid into butyric acid with the concomitant production of $\mathrm{CO}_{2}$ and $\mathrm{H}_{2}$ gas at relatively low $\mathrm{pH}$. As an anaerobic spore former, it survives pasteurization and will grow in semihard cheese resulting in off-flavors and excessive gas formation. Low contamination levels of spores of butyric acid bacteria in pasteurized milk ( 10 spores per liter) can already cause problems. In the Netherlands, a penalty system (based on monthly analysis of spore presence in $2 \times 0.1 \mathrm{ml}$ of delivered raw milk) is implemented for the farmers to control the contamination of farm tank milk with these spores. The Dutch dairy industry wants to ensure a contamination level of butyric acid spores below a maximum spore limit (MSL) of 1000 spores per liter raw milk [62]. Butyric acid spores originate from the farm environment, such as soil, silage, and other feed and are transferred to the raw milk mainly via the fecal contamination of cow's teats as already described for $B$. cereus (see Section 2.3; Figure 2). In a modeling study as well as a year-long survey on 24 Dutch dairy farms, it was found that the contamination level of silage is the most important factor for the contamination level of farm tank milk: feeding silage containing not more than 3 log butyric acid spores per gram, combined with a basic pretreatment of the teats before milking, is sufficient to assure the MSL $[62,63]$. Hygiene measures aiming at improving the barn hygiene and decreasing the transmission of spores, originating directly from soil during milking, and reducing the contamination level of other feed seemed to contribute only marginally to an improvement of the control of the contamination of farm tank milk with butyric acid spores. However, undoubtedly the primary source of these spores in silage is soil which contains high levels of butyric acid spores (mean of $4.2 \mathrm{log}$ spores per gram; Table 2). One of the risk factors associated with high levels of spores in silage is the initial contamination of silage with soil via enclosure of soil during harvesting. Furthermore, high concentrations of butyric acid spores in (corn) silage seem to be the result of oxygen penetration into the silage (during the storage period and/or after opening of the silo), resulting in aerobic instability (e.g. visible moulds) and formation of anaerobic niches with an increased $\mathrm{pH}$ where locally high concentrations of these spores ( $>5$ log per gram) can develop [10].

\section{Conclusions}

In many types of food and feed, soil can be considered as the initial contamination source for spore formers. Usually, when direct transfer from soil is involved, levels of these spore formers in foods, ingredients, or feeds are too low to cause problems. However, because of the complexity of the food chain, particular spore-forming species or types may encounter niches where proliferation occurs. This can happen on the primary production level (e.g., silage, bedding material), in the processing line (e.g., storage tanks), during distribution (e.g., temperature abuse during refrigerated storage), or in the final product (e.g., complex foods, fruit 
juice). These proliferation steps enable the endospore former such as B. cereus, A. acidoterrestris, C. tyrobutyricum, nonproteolytic C. botulinum or C. estertheticum, either to enter as a contaminant into a next step of the production chain or to provoke food quality or safety problems in the final product. For the food industry, it is a challenge to gain insight into the whole contamination flow of endospore formers originating from soil as well as in the conditions permitting their proliferation.

\section{References}

[1] A. Andersson, U. Ronner, and P. E. Granum, "What problems does the food industry have with the spore-forming pathogens Bacillus cereus and Clostridium perfringens?" International Journal of Food Microbiology, vol. 28, no. 2, pp. 145-155, 1995.

[2] S. Rodgers, "Long shelf life cook-chill technologies: food safety risks and solutions," Food Australia, vol. 55, no. 3, pp. 80-83, 2003.

[3] P. Scheldeman, L. Herman, S. Foster, and M. Heyndrickx, "Bacillus sporothermodurans and other highly heat-resistant spore formers in milk," Journal of Applied Microbiology, vol. 101, no. 3, pp. 542-555, 2006.

[4] M. H. Guinebretière, F. L. Thompson, A. Sorokin et al., "Ecological diversification in the Bacillus cereus group," Environmental Microbiology, vol. 10, no. 4, pp. 851-865, 2008.

[5] S. Vilain, Y. Luo, M. B. Hildreth, and V. S. Brözel, "Analysis of the life cycle of the soil saprophyte Bacillus cereus in liquid soil extract and in soil," Applied and Environmental Microbiology, vol. 72, no. 7, pp. 4970-4977, 2006.

[6] H. König, "Bacillus species in the intestine of termites and other soil invertebrates," Journal of Applied Microbiology, vol. 101, no. 3, pp. 620-627, 2006.

[7] G. B. Jensen, B. M. Hansen, J. Eilenberg, and J. Mahillon, "The hidden lifestyles of Bacillus cereus and relatives," Environmental Microbiology, vol. 5, no. 8, pp. 631-640, 2003.

[8] F. Carlin, J. Brillard, V. Broussolle et al., "Adaptation of Bacillus cereus, an ubiquitous worldwide-distributed foodborne pathogen, to a changing environment," Food Research International, vol. 43, no. 7, pp. 1885-1894, 2010.

[9] M. M. M. Vissers, M. C. te Giffel, F. Driehuis, P. De Jong, and J. M. G. Lankveld, "Minimizing the level of Bacillus cereus spores in farm tank milk," Journal of Dairy Science, vol. 90, no. 7, pp. 3286-3293, 2007.

[10] M. M. M. Vissers, F. Driehuis, M. C. te Giffel, P. De Jong, and J. M. G. Lankveld, "Minimizing the level of butyric acid bacteria spores in farm tank milk," Journal of Dairy Science, vol. 90, no. 7, pp. 3278-3285, 2007.

[11] M. Nevas, M. Lindström, A. Hörman, R. Keto-Timonen, and H. Korkeala, "Contamination routes of Clostridium botulinum in the honey production environment," Environmental Microbiology, vol. 8, no. 6, pp. 1085-1094, 2006.

[12] C. Lúquez, M. I. Bianco, L. I. T. de Jong et al., "Distribution of botulinum toxin-producing clostridia in soils of Argentina," Applied and Environmental Microbiology, vol. 71, no. 7, pp. 4137-4139, 2005.

[13] J. Li, S. Sayeed, and B. A. McClane, "Prevalence of enterotoxigenic Clostridium perfringens isolates in Pittsburgh (Pennsylvania) area soils and home kitchens," Applied and Environmental Microbiology, vol. 73, no. 22, pp. 7218-7224, 2007.
[14] G. Moschonas, D. J. Bolton, J. J. Sheridan, and D. A. McDowell, "Isolation and sources of blown pack spoilage clostridia in beef abattoirs," Journal of Applied Microbiology, vol. 107, no. 2, pp. 616-624, 2009.

[15] M. C. Julien, P. Dion, C. Lafrenière, H. Antoun, and P. Drouin, "Sources of clostridia in raw milk on farms," Applied and Environmental Microbiology, vol. 74, no. 20, pp. 6348-6357, 2008.

[16] X. Y. Wu, M. Walker, B. Vanselow, R. L. Chao, and J. Chin, "Characterization of mesophilic Bacilli in faeces of feedlot cattle," Journal of Applied Microbiology, vol. 102, no. 3, pp. 872-879, 2007.

[17] M. Magnusson, A. Christiansson, and B. Svensson, "Bacillus cereus spores during housing of dairy cows: factors affecting contamination of raw milk," Journal of Dairy Science, vol. 90, no. 6, pp. 2745-2754, 2007.

[18] P. Scheldeman, A. Pil, L. Herman, P. De Vos, and M. Heyndrickx, "Incidence and diversity of potentially highly heat-resistant spores isolated at dairy farms," Applied and Environmental Microbiology, vol. 71, no. 3, pp. 1480-1494, 2005.

[19] L. P. Stenfors Arnesen, A. Fagerlund, and P. E. Granum, "From soil to gut: Bacillus cereus and its food poisoning toxins," FEMS Microbiology Reviews, vol. 32, no. 4, pp. 579-606, 2008.

[20] J. Bassett and P. McClure, "A risk assessment approach for fresh fruits," Journal of Applied Microbiology, vol. 104, no. 4, pp. 925-943, 2008.

[21] K. Frederiksen, H. Rosenquist, K. Jørgensen, and A. Wilcks, "Occurrence of natural Bacillus thuringiensis contaminants and residues of Bacillus thuringiensis-based insecticides on fresh fruits and vegetables," Applied and Environmental Microbiology, vol. 72, no. 5, pp. 3435-3440, 2006.

[22] Y. P. de Vries, Bacillus cereus spore formation, structure, and germination, Ph.D. thesis, 2011.

[23] J. G. E. Wijman, P. P. L. A. de Leeuw, R. Moezelaar, M. H. Zwietering, and T. Abee, "Air-liquid interface biofilms of Bacillus cereus: formation, sporulation, and dispersion," Applied and Environmental Microbiology, vol. 73, no. 5, pp. 1481-1488, 2007.

[24] J. H. Ryu and L. R. Beuchat, "Biofilm formation and sporulation by Bacillus cereus on a stainless steel surface and subsequent resistance of vegetative cells and spores to chlorine, chlorine dioxide, and a peroxyacetic acid-based sanitizer," Journal of Food Protection, vol. 68, no. 12, pp. 2614-2622, 2005.

[25] F. Carlin, M. Fricker, A. Pielaat et al., "Emetic toxin-producing strains of Bacillus cereus show distinct characteristics within the Bacillus cereus group," International Journal of Food Microbiology, vol. 109, no. 1-2, pp. 132-138, 2006.

[26] EFSA (European Food Safety Authority), "Opinion of the scientific panel on biological hazards on Bacillus cereus and other Bacillus sp. in foodstuffs," EFSA Journal, vol. 175, pp. $1-49,2004$.

[27] M. Heyndrickx, S. Marchand, V. De Jonghe, K. Smet, K. Coudijzer, and J. De Block, "Understanding and preventing consumer milk microbial spoilage and chemical deterioration," in Improving the Safety and Quality of Milk, M. W. Griffiths, Ed., vol. 2 of Improving Quality in Milk Products, pp. 97135, Woodhead Publishing Limited, Cambridge, UK, 2010.

[28] B. Svensson, A. Monthán, M. H. Guinebretière, C. NguyenThé, and A. Christiansson, "Toxin production potential and the detection of toxin genes among strains of the Bacillus cereus group isolated along the dairy production chain," International Dairy Journal, vol. 17, no. 10, pp. 1201-1208, 2007. 
[29] A. Coorevits, V. De Jonghe, J. Vandroemme et al., "Comparative analysis of the diversity of aerobic spore-forming bacteria in raw milk from organic and conventional dairy farms," Systematic and Applied Microbiology, vol. 31, no. 2, pp. 126-140, 2008.

[30] M. C. te Giffel, A. Wagendorp, A. Herrewegh, and F. Driehuis, "Bacterial spores in silage and raw milk," Antonie van Leeuwenhoek, vol. 81, no. 1-4, pp. 625-630, 2002.

[31] M. M. M. Vissers, M. C. te Giffel, F. Driehuis, P. De Jong, and J. M. G. Lankveld, "Predictive modeling of Bacillus cereus spores in farm tank milk during grazing and housing periods," Journal of Dairy Science, vol. 90, no. 1, pp. 281-292, 2007.

[32] A. Christiansson, J. Bertilsson, and B. Svensson, "Bacillus cereus spores in raw milk: factors affecting the contamination of milk during the grazing period," Journal of Dairy Science, vol. 82, no. 2, pp. 305-314, 1999.

[33] C. L. Little and I. A. Gillespie, "Prepared salads and public health," Journal of Applied Microbiology, vol. 105, no. 6, pp. 1729-1743, 2008.

[34] T. Lund, M. L. De Buyser, and P. E. Granum, "A new cytotoxin from Bacillus cereus that may cause necrotic enteritis," Molecular Microbiology, vol. 38, no. 2, pp. 254-261, 2000.

[35] F. Carlin, M. H. Guinebretiere, C. Choma, R. Pasqualini, A. Braconnier, and C. Nguyen-The, "Spore-forming bacteria in commercial cooked, pasteurised and chilled vegetable purees," Food Microbiology, vol. 17, no. 2, pp. 153-165, 2000.

[36] M. H. Guinebretière and C. Nguyen-The, "Sources of Bacillus cereus contamination in a pasteurized zucchini purée processing line, differentiated by two PCR-based methods," FEMS Microbiology Ecology, vol. 43, no. 2, pp. 207-215, 2003.

[37] A. L. Afchain, F. Carlin, C. Nguyen-The, and I. Albert, "Improving quantitative exposure assessment by considering genetic diversity of B. cereus in cooked, pasteurised and chilled foods," International Journal of Food Microbiology, vol. 128, no. 1, pp. 165-173, 2008.

[38] N. Jensen, "Alicyclobacillus - a new challenge for the food industry," Food Australia, vol. 51, no. 1-2, pp. 33-36, 1999.

[39] K. Goto, H. Matsubara, K. Mochida et al., "Alicyclobacillus herbarius sp. nov., a novel bacterium containing $\omega$-cycloheptane fatty acids, isolated from herbal tea," International Journal of Systematic and Evolutionary Microbiology, vol. 52, no. 1, pp. 109-113, 2002.

[40] K. Goto, K. Mochida, M. Asahara, M. Suzuki, H. Kasai, and A. Yokota, "Alicyclobacillus pomorum sp. nov., a novel thermoacidophilic, endospore-forming bacterium that does not possess $\omega$-alicyclic fatty acids, and emended description of the genus Alicyclobacillus," International Journal of Systematic and Evolutionary Microbiology, vol. 53, no. 5, pp. 1537-1544, 2003.

[41] H. Matsubara, K. Goto, T. Matsumura et al., "Alicyclobacillus acidiphilus sp. nov., a novel thermo-acidophilic, $\omega$-alicyclic fatty acid-containing bacterium isolated from acidic beverages," International Journal of Systematic and Evolution-ary Microbiology, vol. 52, no. 5, pp. 1681-1685, 2002.

[42] F. M. Silva, P. Gibbs, M. C. Vieira, and C. L. M. Silva, "Thermal inactivation of Alicyclobacillus acidoterrestris spores under different temperature, soluble solids and $\mathrm{pH}$ conditions for the design of fruit processes," International Journal of Food Microbiology, vol. 51, no. 2-3, pp. 95-103, 1999.

[43] N. Jensen and F. B. Whitfield, "Role of Alicyclobacillus acidoterrestris in the development of a disinfectant taint in shelf-stable fruit juice," Letters in Applied Microbiology, vol. 36, no. 1, pp. 9-14, 2003.

[44] M. Walker and C. A. Phillips, "Alicyclobacillus acidoterrestris: an increasing threat to the fruit juice industry?" International
Journal of Food Science and Technology, vol. 43, no. 2, pp. 250-260, 2008.

[45] I. C. McKnight, M. N. U. Eiroa, A. S. Sant'Ana, and P. R. Massaguer, "Alicyclobacillus acidoterrestris in pasteurized exotic Brazilian fruit juices: isolation, genotypic characterization and heat resistance," Food Microbiology, vol. 27, no. 8, pp. 1016-1022, 2010.

[46] M. E. Parish and R. M. Goodrich, "Recovery of presumptive Alicyclobacillus strains from orange fruit surfaces," Journal of Food Protection, vol. 68, no. 10, pp. 2196-2200, 2005.

[47] S. Mcintyre, J. Y. Ikawa, N. Parkinson, J. Haglund, and J. Lee, "Characteristics of an acidophilic Bacillus strain isolated from shelf-stable juices," Journal of Food Protection, vol. 58, no. 3, pp. 319-321, 1995.

[48] M. Heyndrickx and P. Scheldeman, "Bacilli associated with spoilage in dairy and other food products," in Applications and Systematics of Bacillus and Relatives, R. Berkely, M. Heyndrickx, N. A. Logan, and P. De Vos, Eds., pp. 64-82, Blackwell Science, Oxford, UK, 2002.

[49] W. H. Groenewald, P. A. Gouws, and R. C. Witthuhn, "Isolation and identification of species of Alicyclobacillus from orchard soil in the Western Cape, South Africa," Extremophiles, vol. 12, no. 1, pp. 159-163, 2008.

[50] K. Goto, A. Nishibori, Y. Wasada, K. Furuhata, M. Fukuyama, and M. Hara, "Identification of thermo-acidophilic bacteria isolated from the soil of several Japanese fruit orchards," Letters in Applied Microbiology, vol. 46, no. 3, pp. 289-294, 2008.

[51] W. H. Groenewald, P. A. Gouws, and R. C. Witthuhn, "Isolation, identification and typification of Alicyclobacillus acidoterrestris and Alicyclobacillus acidocaldarius strains from orchard soil and the fruit processing environment in South Africa," Food Microbiology, vol. 26, no. 1, pp. 71-76, 2009.

[52] G. W. Gould, "History of science-spores: Lewis B Perry Memorial Lecture 2005," Journal of Applied Microbiology, vol. 101, no. 3, pp. 507-513, 2006.

[53] J. D. Kim, D. W. Lee, K. S. Lee, C. H. Choi, and K. H. Kang, "Distribution and antimicrobial susceptibility of Clostridium species in soil contaminated with domestic livestock feces of Korea," Journal of Microbiology and Biotechnology, vol. 14, no. 2, pp. 401-410, 2004.

[54] M. Del Mar Gamboa, E. Rodríguez, and P. Vargas, "Diversity of mesophilic clostridia in Costa Rican soils," Anaerobe, vol. 11, no. 6, pp. 322-326, 2005.

[55] J. D. Kim, D. W. Lee, K. S. Lee, C. H. Choi, and K. H. Kang, "Distribution and antimicrobial susceptibility of Clostridium species in soil contaminated with domestic livestock feces of Korea," Journal of Microbiology and Biotechnology, vol. 14, no. 2, pp. 401-410, 2004.

[56] M. W. Peck, K. E. Goodburn, R. P. Betts, and S. C. Stringer, "Assessment of the potential for growth and neurotoxin formation by non-proteolytic Clostridium botulinum in short shelf-life commercial foods designed to be stored chilled," Trends in Food Science and Technology, vol. 19, no. 4, pp. 207-216, 2008.

[57] M. Lindström, K. Kiviniemi, and H. Korkeala, "Hazard and control of group II (non-proteolytic) Clostridium botulinum in modern food processing," International Journal of Food Microbiology, vol. 108, no. 1, pp. 92-104, 2006.

[58] K. H. Adam, S. H. Flint, and G. Brightwell, "Psychrophilic and psychrotrophic clostridia: sporulation and germination processes and their role in the spoilage of chilled, vacuumpackaged beef, lamb and venison," International Journal of Food Science and Technology, vol. 45, no. 8, pp. 1539-1544, 2010. 
[59] D. M. Broda, R. G. Bell, J. A. Boerema, and D. R. Musgrave, "The abattoir source of culturable psychrophilic Clostridium spp. causing 'blown pack' spoilage of vacuum-packed chilled venison," Journal of Applied Microbiology, vol. 93, no. 5, pp. 817-824, 2002.

[60] J. A. Boerema, D. M. Broda, and R. G. Bell, "Abattoir sources of psychrophilic clostridia causing blown pack spoilage of vacuum-packed chilled meats determined by culture-based and molecular detection procedures," Letters in Applied Microbiology, vol. 36, no. 6, pp. 406-411, 2003.

[61] R. M. Clemens, K. H. Adam, and G. Brightwell, "Contamination levels of Clostridium estertheticum spores that result in gaseous spoilage of vacuum-packaged chilled beef and lamb meat," Letters in Applied Microbiology, vol. 50, no. 6, pp. 591-596, 2010.

[62] M. M. M. Vissers, F. Driehuis, M. C. te Giffel, P. De Jong, and J. M. G. Lankveld, "Concentrations of butyric acid bacteria spores in silage and relationships with aerobic deterioration," Journal of Dairy Science, vol. 90, no. 2, pp. 928-936, 2007.

[63] M. M. M. Vissers, F. Driehuis, M. C. te Giffel, P. De Jong, and J. M. G. Lankveld, "Improving farm management by modeling the contamination of farm tank milk with butyric acid bacteria," Journal of Dairy Science, vol. 89, no. 3, pp. 850-858, 2006. 

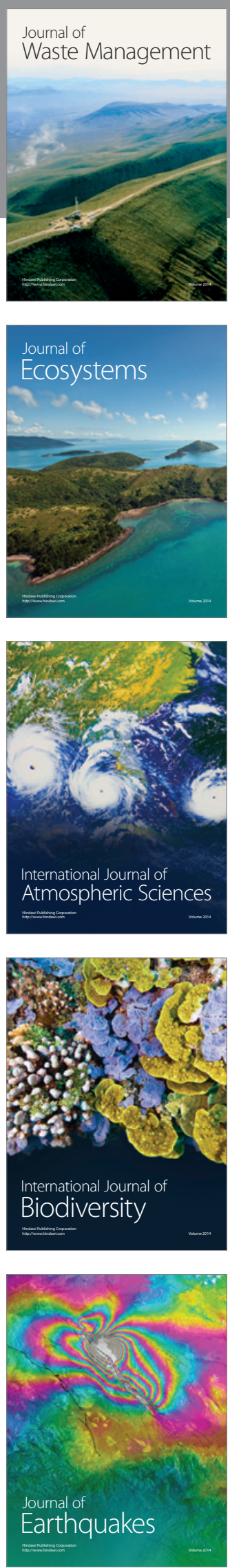
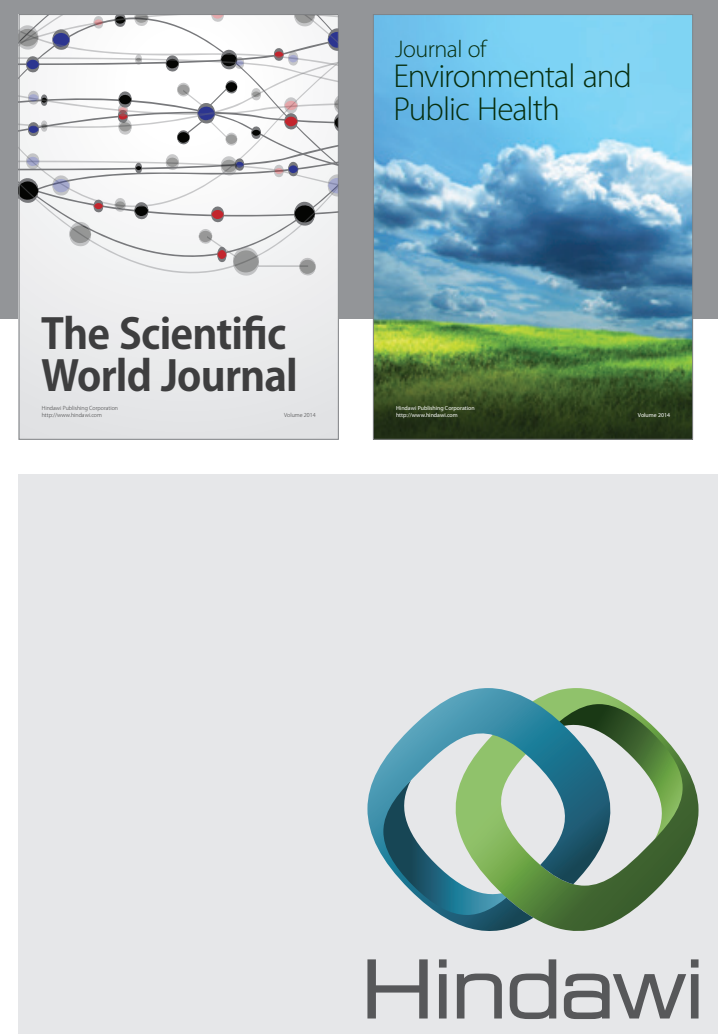

Submit your manuscripts at

http://www.hindawi.com
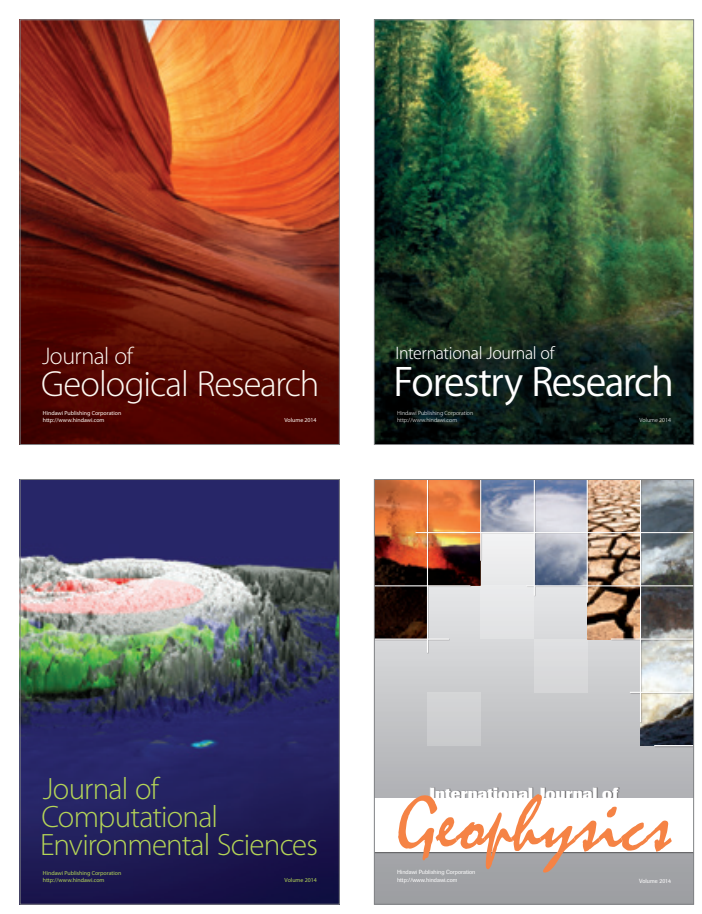
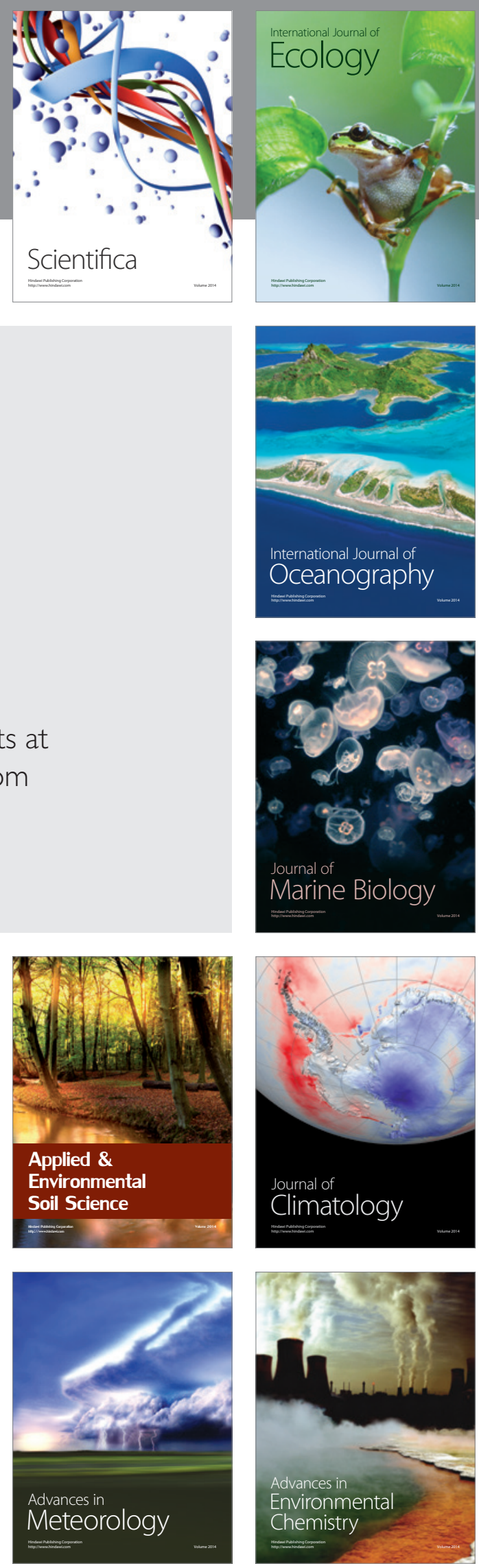